\title{
INVESTIGATION OF CARBON NANOMATERIAL INLFUENCE ON PHOTOCATALYTIC PROPERTIES OF TIO
}

\author{
Ainars Knoks ${ }^{1}$, Raitis Sika ${ }^{1,2}$, Roberts Olins ${ }^{1,2}$, Peteris Lesnicenoks ${ }^{1,2}$ \\ ${ }^{1}$ Institute of Solid State Physics, University of Latvia, Latvia; ${ }^{2}$ University of Latvia, Latvia \\ ainars.knoks@cfi.lu.lv, raitis.sika@cfi.lu.lv, roberts.olins@cfi.lu.lv, peteris.lesnicenoks@cfi.lu.lv
}

\begin{abstract}
One of industrial activity (agriculture and other) problems is the leftover materials that seep into soil and water. A possible mitigation of this pollution is photocatalytic degradation as it can be installed for passive waste degradation in proximity of water sources or directly in them. A stable and environmentally safe photocatalytic material titanium dioxide $\left(\mathrm{TiO}_{2}\right)$ efficiency can be improved with addition of carbon material. In this work investigation of commercial and synthesized carbon nanomaterial introduction in nanostructured $\mathrm{TiO}_{2}$ has been carried out with the aim to increase the efficiency and lower production costs. The photocatalytic properties of these composite materials are compared. Synthesized nitrogen doped carbon material is compared to commercial carbon doped with platinum. In situ addition to anodic $\mathrm{TiO}_{2}$ and the influence on photocatalytic properties were investigated. As a first step of pollution degradation, methylene blue (MB) degradation has been compared. It is shown that commercial $\mathrm{C} / \mathrm{Pt}$ promotes faster $\mathrm{TiO}_{2}$ phase transition to rutile at higher loads and lowers photocurrent response. On the other hand, self-synthesized carbon material promotes charge carrier separation and increases photocurrent response but seems to lower MB degradation with higher loading. Thus, current work indicates that in situ carbon doping increases photocatalytic activity in the visible light region. Synthesized $\mathrm{N}$ doped carbon does not to promote MB degradation in comparison to commercial $\mathrm{C} / \mathrm{Pt}$, but further investigation of the source of variation of activity is necessary as introduction of $\mathrm{C} / \mathrm{Pt}$ brings $\mathrm{TiO}_{2}$ crystallinity changes.
\end{abstract}

Keywords: titanium dioxide, photocatalysis, pollution degradation, carbon materials.

\section{Introduction}

Agriculture in the EU is heading towards limiting and in some cases discontinuing the use of hazardous pesticides and herbicides, as well as various synthetic growth hormone implementation is taking time and some developing countries face longer implementation time. This brings us to a question of safety and regenerative agriculture. Even though some claim that with current regulations the soil and water contamination is within limits, the long-term solution is from minimal to no contamination of herbicides and pesticides. Thus, a mechanism for cleaning water and soil should be implemented. Direct filtration is impossible not only due to the vastness and logistics of such endeavour but also due to fields are mostly at a substantial distance from any cleaning facility. Next possible solution would be introduction of counter active agents, but these can be aggressive to the surrounding environment, not just the target. One possible way of mitigation of this pollution is photocatalytic degradation, as it can be installed for passive waste degradation in proximity of water sources or directly in them.

It is well known that material activity and efficiency can be increased by nanofabrication, but for such use safety to the environment has to be take $\mathrm{n}$ into account, i.e. not only cytotoxicity [1] but also recyclability and life time. As aforementioned pollution is in remote locations material with long lifetime and activity without external power supply should be used, indicating that photocatalytic degradation could be the solution. Similarly to $\mathrm{CO} 2$ reduction [2;3], hydrogen production [4] or waste treatment [5], [6] the photocatalytically active materials can carry out this work. One of suitable materials is $\mathrm{TiO} 2$ as the synthesis variation is vast, i.e. thin films [7], core-shell [8], nanotube [9;10], nanoparticles [11], modification possibilities [12-16] and it is considered safe [11; 17]. but pristine $\mathrm{TiO} 2$ has flaws, the absorption edge is in the UV region and efficiency losses due to recombination of light-induced charge carriers.

To redshift the absorption edge and increase activity of sheet $\mathrm{TiO}_{2}$ a scalable method of synthesis should be chosen. It is known that by addition of various materials it is possible to achieve a change in the absorption edge and slow the recombination rate. But it is not clear what material would be safe and active for reduction of pesticides and herbicides. Adding precious metals to $\mathrm{TiO}_{2}$ can increase the activity, but it also increases the price of production. Thus, abundant material as carbon could be used to gain similar activity and lower production costs.

In this work investigation of carbon nanomaterial influence on nanostructured $\mathrm{TiO}_{2}$ has been carried out to investigate the photocatalytic properties of composite material for the final goal of pollution 
degradation. Synthesized carbon material dopped with nitrogen is compared to commercial C/Pt. As the first step of pollution degradation, methylene blue (MB) decomposition has been compared and conclusions on the carbon material influence on the photocatalytic properties are drawn.

\section{Materials and methods}

Samples were prepared by a two step anodization process. Preparation of samples was carried out by cutting up and cleaning a piece of titanium foil (GoodFellow). Cleaning was performed in ultrasonic bath for 15 minutes in water and then for another 15 minutes in acetone. Electrolyte consisting of $50 \mathrm{~g}$ ethylene glycol; $2 \mathrm{~g}$ water and $0.152 \mathrm{~g}$ of ammonium fluoride $\left(\mathrm{NH}_{4} \mathrm{~F}\right.$ Sigma-Aldrich) was prepared. After cleaning each piece Ti foil is place into the electrolyte as an anode and platinum foil used as cathode. First step anodization was carried out at $60 \mathrm{~V}$. Then, $\mathrm{TiO}_{2}$ layer is removed, and samples rinsed with propan-2-ol.

Electrolyte for the second step anodization has the same components as the first step electrolyte. Selected carbon material is added to the electrolyte at chosen amounts. Anodization is carried out at 60 $\mathrm{V}$ again for 1 hour. Two series were synthesized, first with commercial carbon $(\mathrm{C} / \mathrm{Pt})$ identified as $\mathrm{CP}$ series, with platinum and second (NC) identified as NC with synthesized nitrogen doped carbon particles. Self-synthesized NC has been described before [18], carbon material is produced by electrochemical exfoliation of graphite, depending on the electrolyte produced graphene sheet stacks can be doped with nitrogen. In this work, such method for production of NC was used.

After synthesis samples are amorphous, thus treatment is necessary, in this work the samples were heat treated in nitrogen atmosphere flow at $500{ }^{\circ} \mathrm{C}$ for 120 minutes. The prepared sample parameters are available in Table 1.

Table 1

Synthesis parameter summary

\begin{tabular}{|c|c|c|c|c|c|}
\hline ID & $\begin{array}{c}\text { Added } \\
\text { material }\end{array}$ & $\begin{array}{c}\text { Added } \\
\text { amount, } \\
\mathbf{w t} \%\end{array}$ & ID & $\begin{array}{c}\text { Added } \\
\text { material }\end{array}$ & $\begin{array}{c}\text { Added } \\
\text { amount, } \\
\mathbf{w t} \%\end{array}$ \\
\hline $\mathrm{CP} 1$ & $\mathrm{n} . \mathrm{a}$. & 0.000 & $\mathrm{NC} 1$ & n.a. & 0.000 \\
\hline $\mathrm{CP} 2$ & $\mathrm{C} / \mathrm{Pt}$ & 0.001 & $\mathrm{NC} 2$ & $\mathrm{NC}$ & 0.001 \\
\hline $\mathrm{CP} 3$ & $\mathrm{C} / \mathrm{Pt}$ & 0.002 & $\mathrm{NC} 3$ & $\mathrm{NC}$ & 0.002 \\
\hline $\mathrm{CP} 4$ & $\mathrm{C} / \mathrm{Pt}$ & 0.010 & $\mathrm{NC} 4$ & $\mathrm{NC}$ & 0.010 \\
\hline $\mathrm{CP} 5$ & $\mathrm{C} / \mathrm{Pt}$ & 0.020 & $\mathrm{NC} 5$ & $\mathrm{NC}$ & 0.020 \\
\hline $\mathrm{CP} 6$ & $\mathrm{C} / \mathrm{Pt}$ & 0.080 & $\mathrm{NC} 6$ & $\mathrm{NC}$ & 0.080 \\
\hline
\end{tabular}

The sample structure was investigated using Raman spectroscopy and X-Ray diffractogram (XRD). Photocatalytic activity was investigated using a 3 electrode cell, evaluation of photocurrent response (PCR) and open circuit potential (OCP) and methylene blue (MB) degradation. Charge carrier generation was determined using chopped light modulation and a $150 \mathrm{~W}$ xenon lamp as a light source, data collected with potentiostat Autolab. Measurements were carried out in 3 electrode setup using 1M $\mathrm{KOH}$ solution purged with Argon gas for 15 minutes prior to measurement, HANNA instruments calomel reference electrode (SCE) was used as a reference electrode, platinum black was used as a counter electrode and samples as the working electrode. For estimation of the charge carrier density and working potential the Mott-Schottky method [19-21] was applied to determine the flat band potential and the charge carrier density.

MB degradation was carried out for 120 minutes. Starting from $0.034 \mathrm{mM}$ solution, sample held in darkness in MB solution prior to turning on irradiation to account for MB adsorption on the surface. The previously used xenon lamp was also used here. Absorption spectrum was taken every 15 minutes for the duration of the experiment.

\section{Results and discussion}

Investigation of the sample structure was done with Raman spectroscopy and XRD. Raman spectra for CP samples (see Fig. 1) and for NC samples (see Fig. 2) shows different reaction to addition of carbon material. We see that increasing $\mathrm{C} / \mathrm{Pt}$ loading increases the carbon modes $\mathrm{D}$ and $\mathrm{G}$ at $1359 \mathrm{~cm}^{-1}$ 
and $1601 \mathrm{~cm}^{-1}$ respectively, noting also D2 mode in higher loading samples, as seen in Fig. 3. No clear change in $\mathrm{TiO}_{2}$ structure can be seen, as Raman investigation shows pure anatase phase. Similarly, for samples with $\mathrm{NC}$, we see no indication of phase mixture, as seen by anatase $\mathrm{TiO}_{2}$ modes $\mathrm{E}_{\mathrm{g}(1)}, \mathrm{E}_{\mathrm{g}(2)}, \mathrm{B}_{1 \mathrm{~g}}$, $\mathrm{E}_{\mathrm{g}(3)}$ respectively at $144,198,395,513$ and $632 \mathrm{~cm}^{-1}[10 ; 22-24]$.

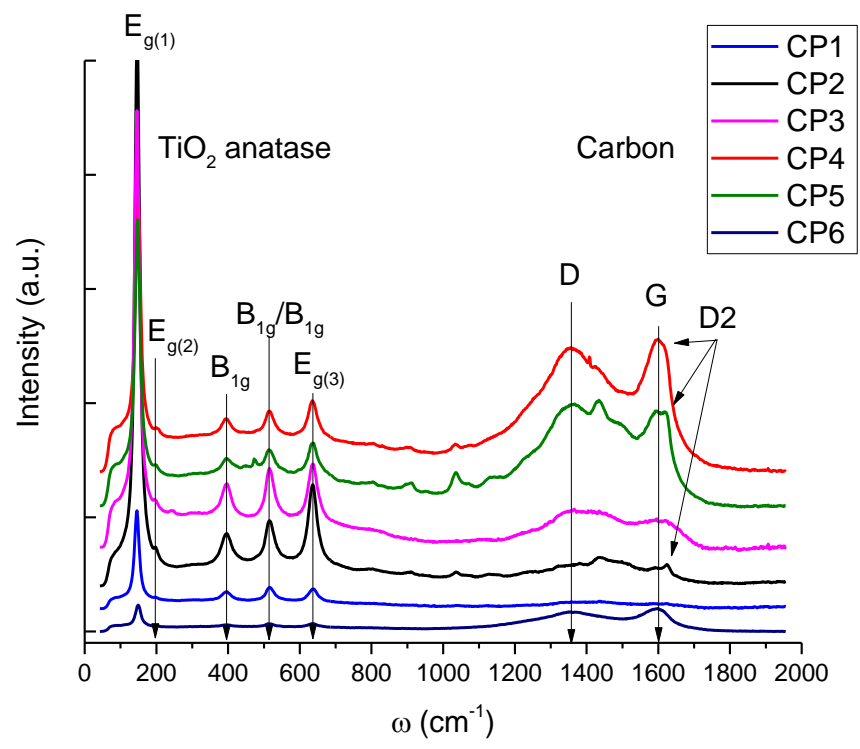

Fig. 1. Raman spectra of CP series

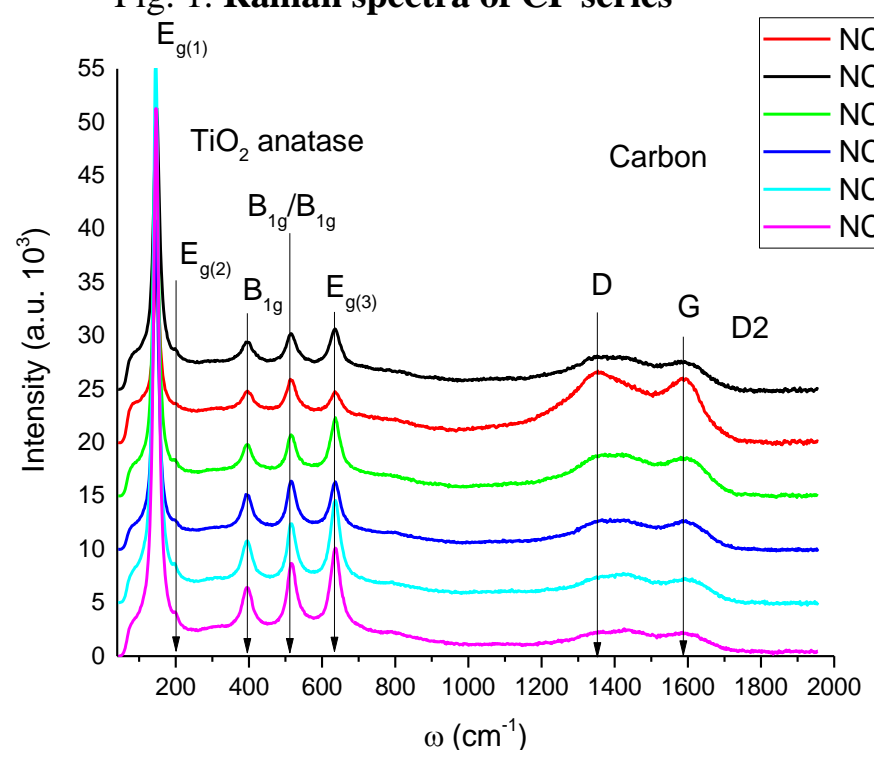

Fig. 2. Raman spectra of NC series

$\mathrm{XRD}$ data clearly show first, $\mathrm{TiO}_{2}$ is in anatase and rutile mix, as clearly seen in Fig. 4. $\mathrm{TiO}_{2}$ anatase (101) strong peak is at $25^{\circ}$ and rutile at $27^{\circ}$ (additional to others, but we will focus on these), as we can see in Fig. 5. Peak at $25^{\circ}$ shifts indicating a change in the lattice size and the rutile peak decreases with introduction of NC. Additionally, we can see that at most loading of NC strong carbon peak is seen at $16^{\circ}$ and $14^{\circ}$ that is not present in low loading samples. On the other hand, for CP series it is the opposite, it starts at mainly anatase and increasing $\mathrm{CP}$ loading enables the phase transition into rutile as indicated by appearance of $27^{\circ}$ peak (as seen in Fig. 6).

Structural investigation shows discrepancy of identified structure, Raman does not show rutile presence change with increased carbon material addition as XRD indicates that structural changes are present mostly under the surface as Raman penetration depth is limited.

As we can see from the structural analysis, transformation of anatase into rutile should red shift the optical absorption edge, thus, for series $\mathrm{CP}$ we expect decreased $\mathrm{E}_{\text {gap }}$ and for $\mathrm{NC}$ slight increase of $\mathrm{E}_{\text {gap }}$ values as anatase $\mathrm{E}_{\text {gap }}$ is $3.2 \mathrm{eV}$ and rutile $3.0 \mathrm{eV}$. 


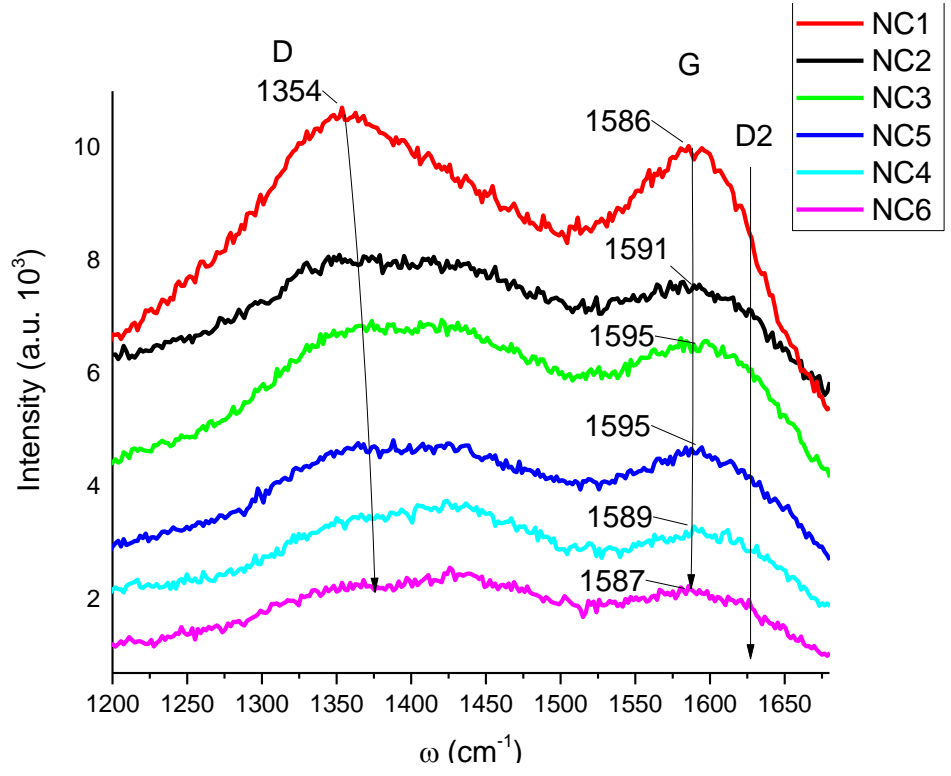

Fig. 3. Raman spectra of carbon modes

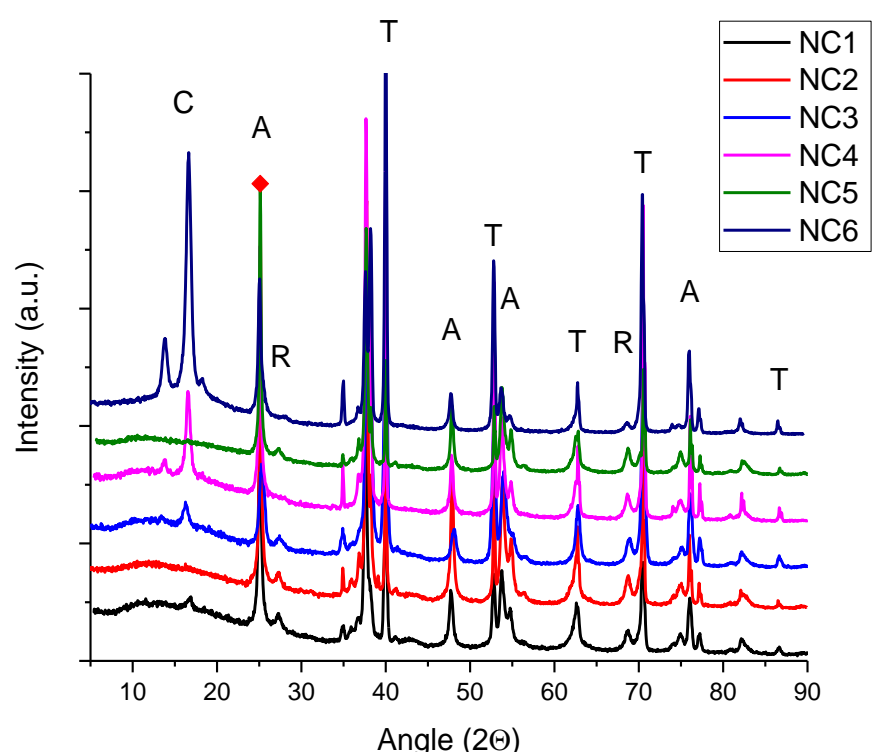

Fig. 4. XRD diffractogram of NC series

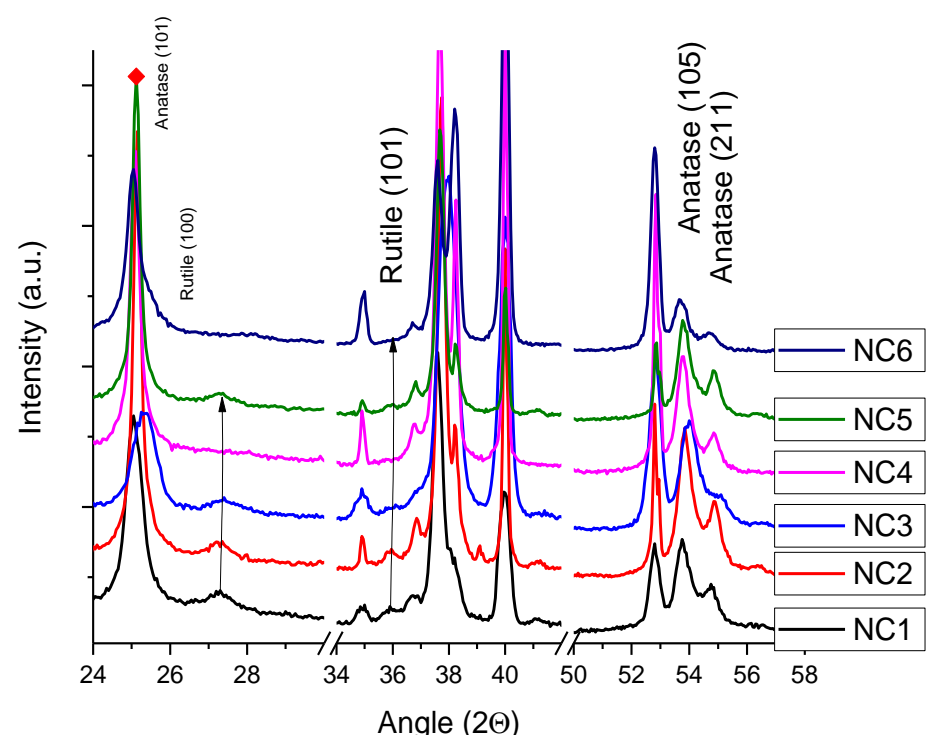

Fig. 5. XRD diffractogram of NC series 


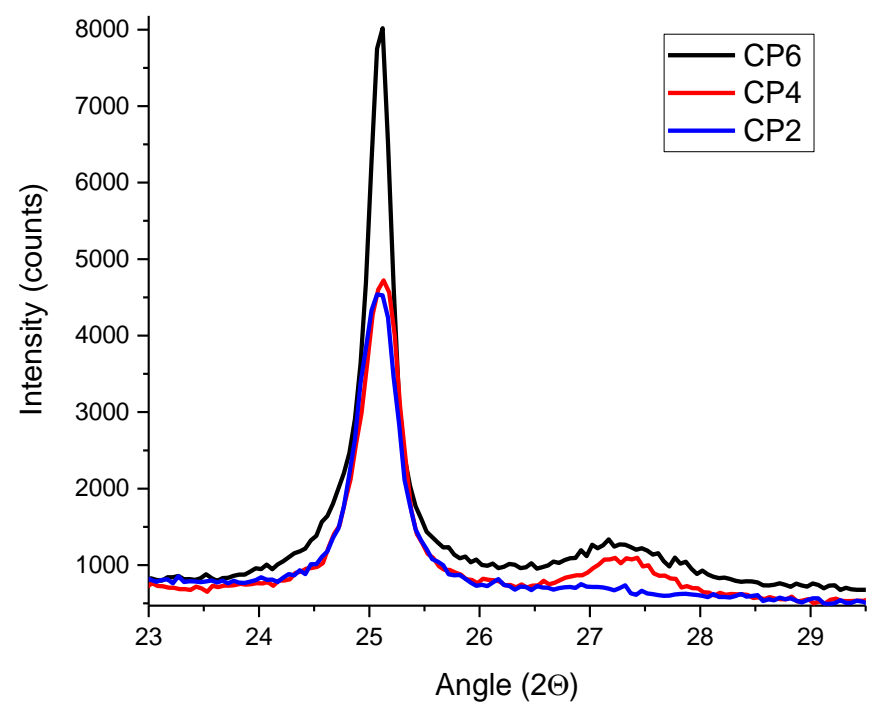

Fig. 6. XRD diffractogram of CP series, increase of XRD Rutile peak

Optical band gap was determined through Kubelka-Munk transformation [25] and use of Tauc plot [26; 27]. The results are depicted in Table 2 . We see that in case of NC increasing carbon material loading decreases $\mathrm{E}_{\text {gap }}$, and for $\mathrm{CP} \mathrm{E}_{\text {gap }}$ values decrease, though, the determined values are a bit high, which indicates a high number of defects. Determined $\mathrm{E}_{\text {gap }}$ values do not provide with the set redshift for increased absorption of radiation.

After MS analysis and calculation of $\mathrm{V}_{\mathrm{Fb}}$ as well as charge carrier density $\mathrm{N}_{\mathrm{D}}$, results are depicted in Figures 7-10. We can see that depending on the loading of commercial carbon material CP charge carrier density increases at the same time the flat band potential becomes more negative, as seen in Fig. 8. On the other hand, synthesized $\mathrm{NC}$ show that a change in flat band potential samples has more positive flat band potential and increased $\mathrm{N}_{\mathrm{D}}$.

The MS investigation shows a change of charge carrier density as well as flat band potential depending on the added amount of carbon material for both $\mathrm{CP}$ and $\mathrm{NC}$ series. We see that influence on the $\mathrm{TiO}_{2}$ is in the opposite directions, CP pushes the flat band potential into more negative values, indicating that to fully estimate the photocatalytic activity of synthesized samples investigation of photoelectrochemical properties and activity was done as described above.

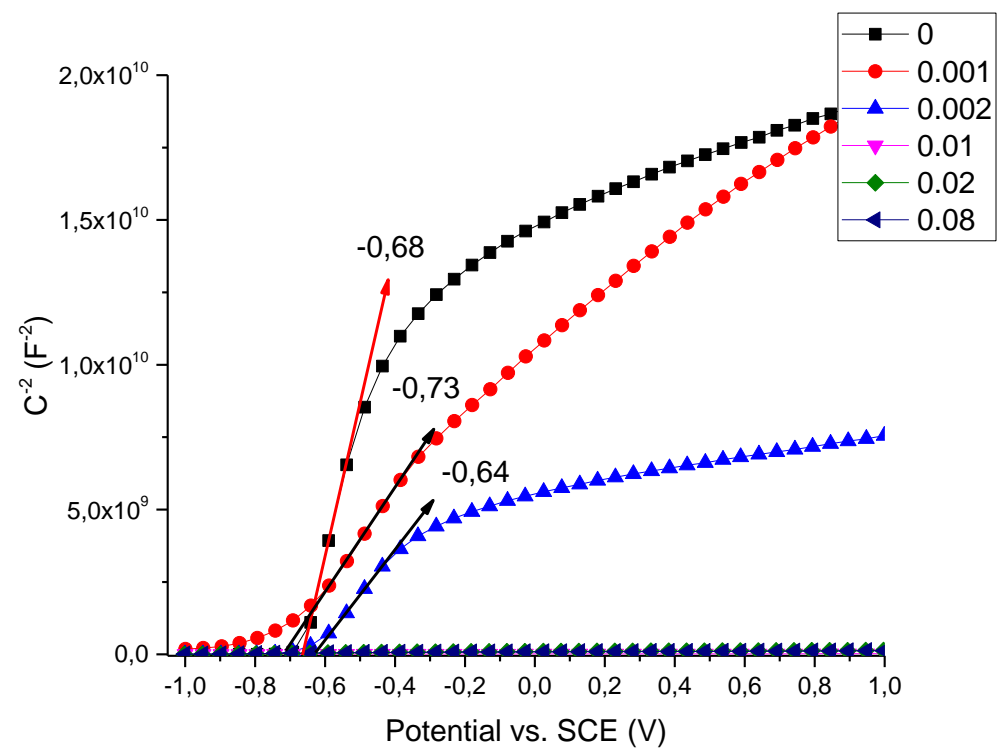

Fig. 7. MS for CP samples square charge carrier density $\mathbf{N}_{D}$ 


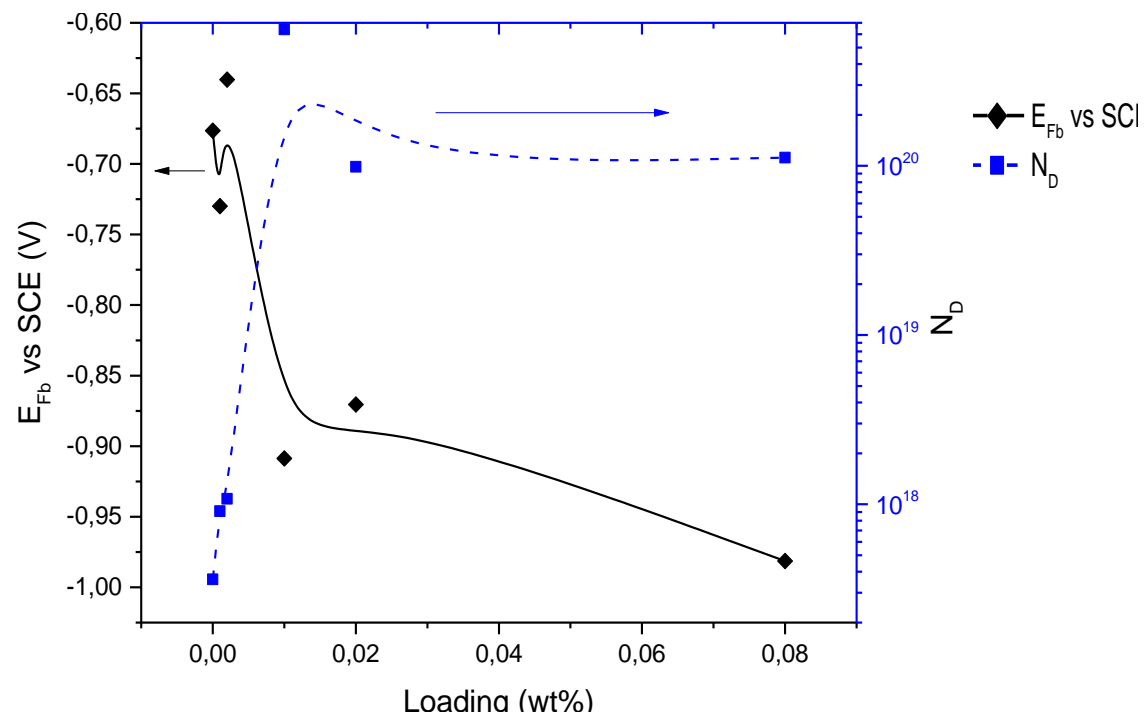

Fig. 8. CP series: black diamond $\mathrm{V}_{\mathrm{Fb}}$ and blue

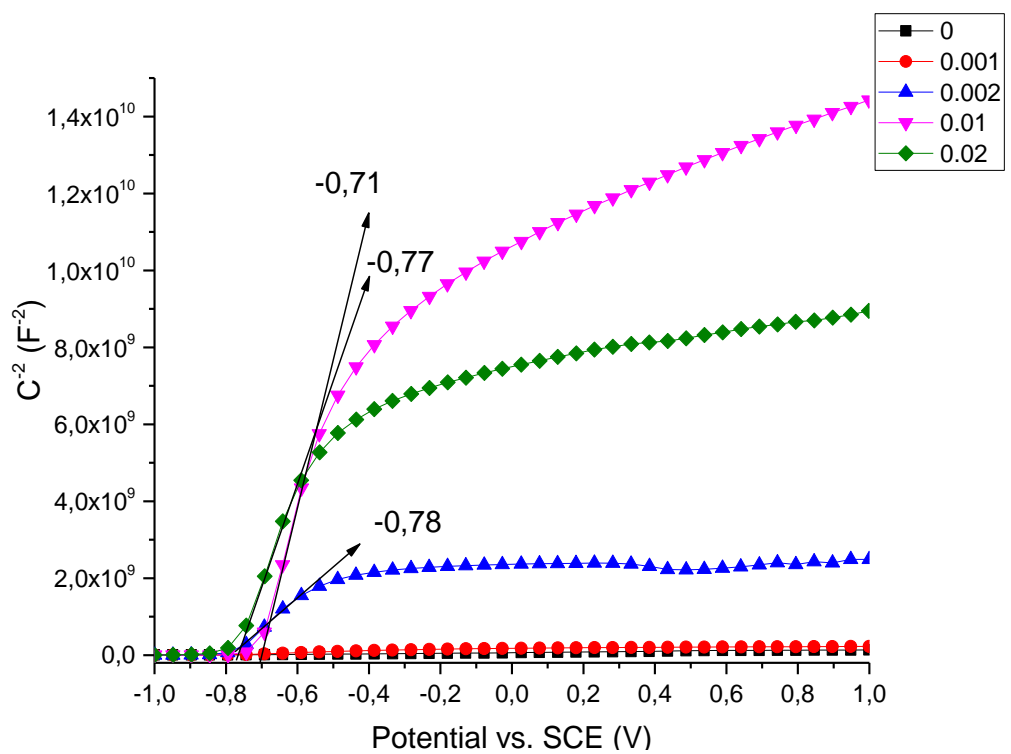

Fig. 9. MS for NC samples blue square charge carrier density $\mathbf{N}_{D}$

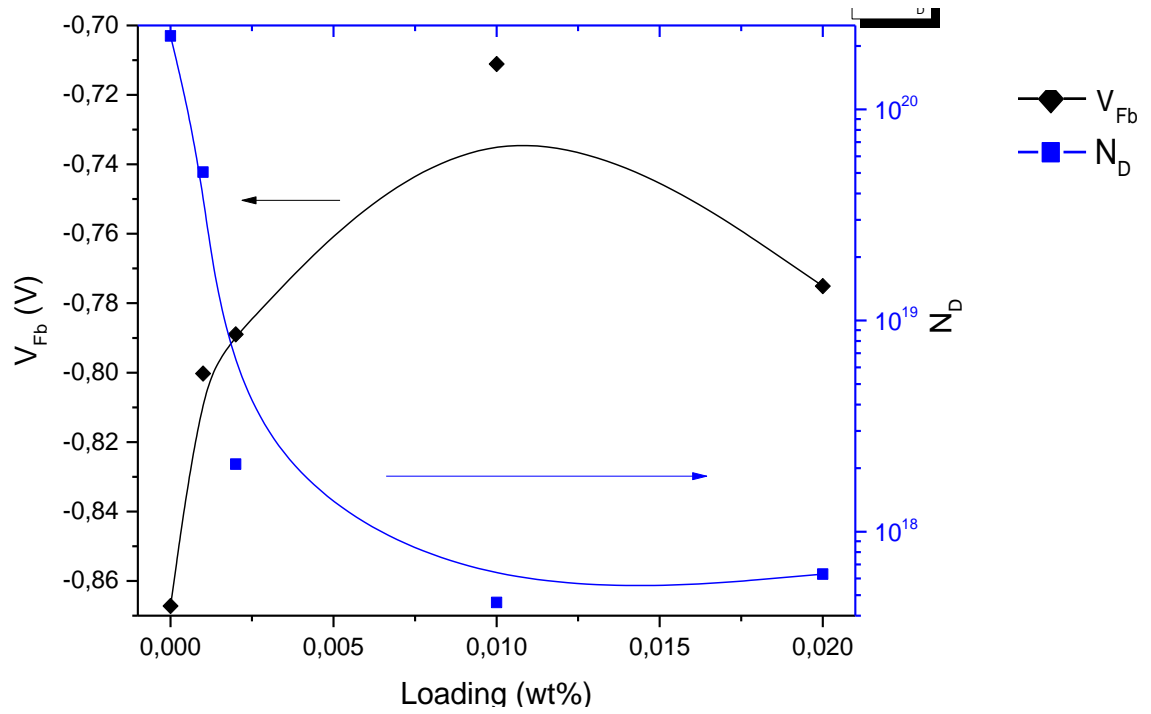

Fig. 10. NC series: black diamond $V_{F b}$ and 
Investigation of the change of photoelectrochemical properties (PCR and OCP but OCP follows similar trends, thus, is not depicted here) we see depicted in Fig. 11 and Fig. 12. In addition to aforementioned values, onset potential was determined and summarised in Table 2 . The increase in NC loading slightly affects PCR (and OCP) values, and shifts the onset potential towards more negative values, on the other hand, addition of CP decreases PCR (and OCP) at the same time shifting onset potential towards more positive values (by $+0.3 \mathrm{~V}$ in this case).

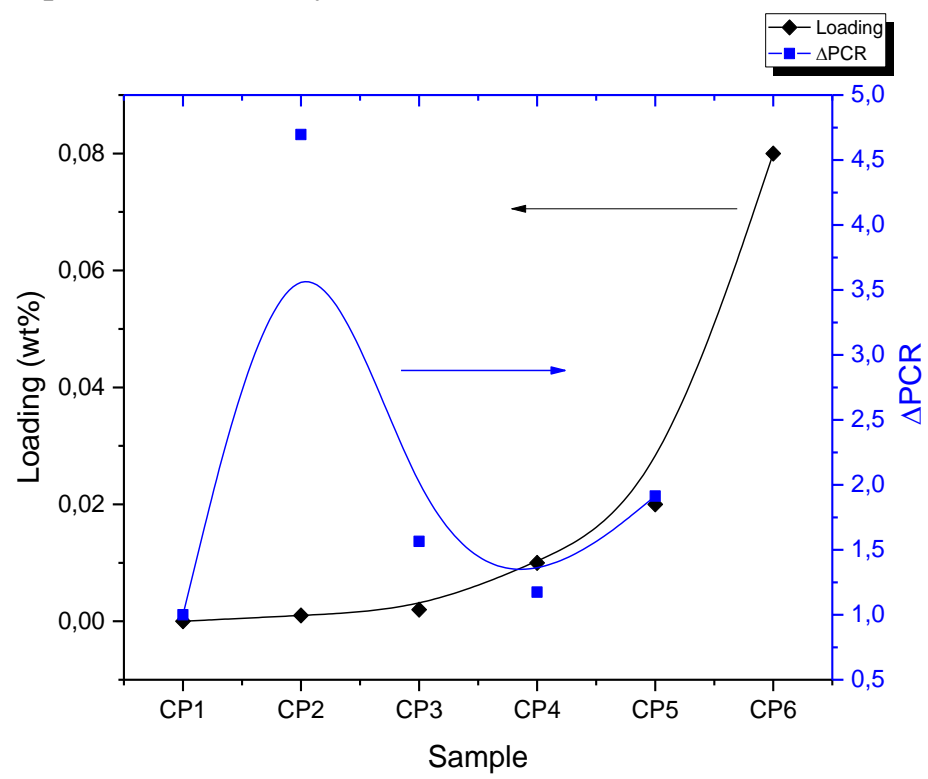

Fig. 11. NC series PCR change comparison

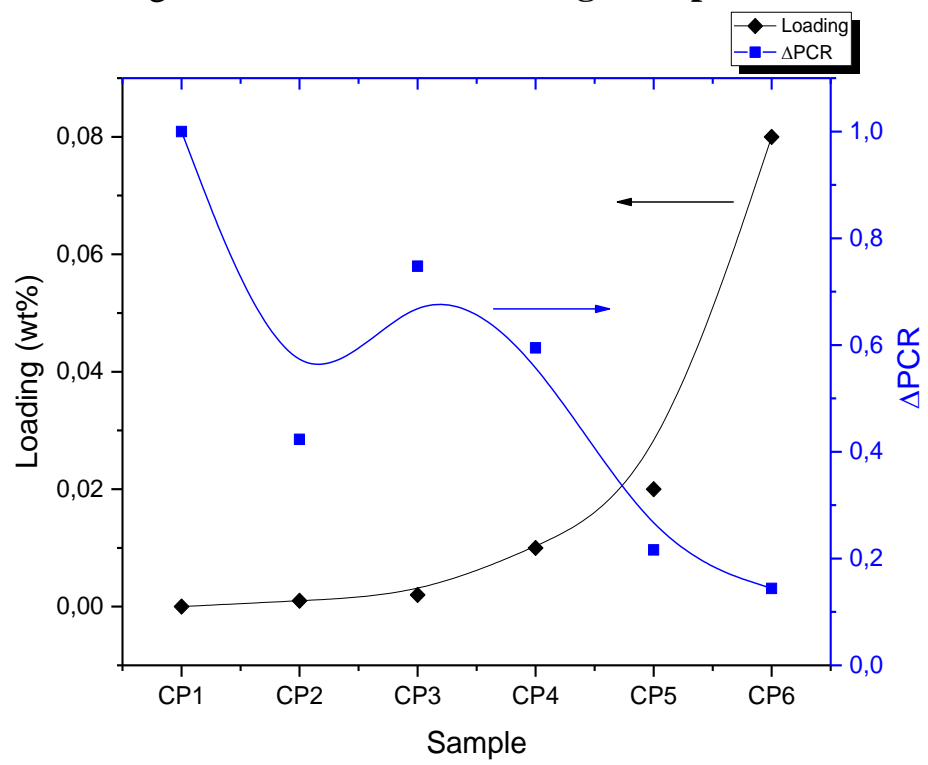

Fig. 12. PCR comparison for CP series

The degradation coefficient was determined by comparing concentration of degraded MB solution and finding rate of change. After the determination of the degradation coefficient $\mathrm{k}$, it was compared to pristine $\mathrm{TiO}_{2}$ of series, showing the growth or decline with addition of carbon material and the results are shown in Fig. 13. From there we see that $\mathrm{CP}$ and $\mathrm{NC}$ have opposite effect on the photocatalytic activity of $\mathrm{TiO}_{2}$. Addition of $\mathrm{CP}$ increases the photocatalytic activity as the degradation coefficient increases with increased load of $\mathrm{CP}$, on the other hand, $\mathrm{NC}$ decrease is seen.

In addition to MB degradation conventional agricultural pesticide/herbicide "Fēniks" was tested. Even though some degradation of the compound was measured, the results are inconclusive at this stage of investigation. 


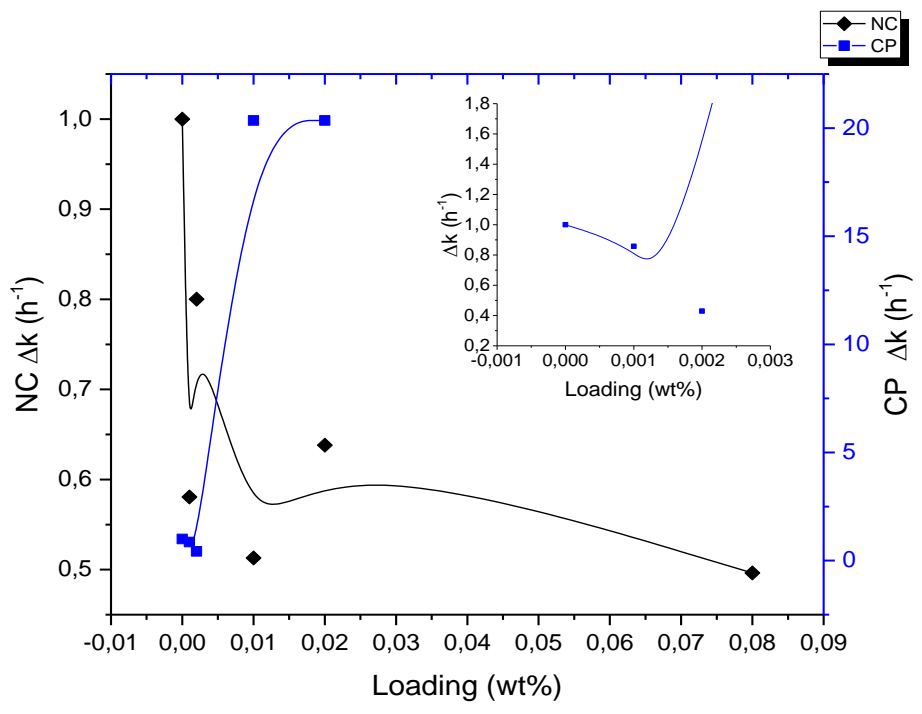

Fig. 13. Degradation coefficient comparison of $\mathrm{CN}$ and NC series change with respect to pristine sample

Table 2

Comparison of sample properties

\begin{tabular}{|c|c|c|c|c|c|c|c|}
\hline Sample & $\mathbf{E}_{\text {gap }}, \mathbf{e V}$ & $\mathbf{\Delta P C R \%}$ & $\mathbf{U}_{\text {Onset, }} \mathbf{V}$ & Sample & Egap, eV & $\mathbf{\Delta P C R \%}$ & $\mathbf{U}_{\text {Onset, }} \mathbf{V}$ \\
\hline NC1 & $3.52 \pm 0.03$ & 1 & $-0.70 \pm 0.05$ & CP1 & $3.79 \pm 0.03$ & 1 & $-0.86 \pm 0.05$ \\
\hline NC2 & 3.48 & 4.69 & -0.80 & CP2 & 3.19 & 0.42 & -1.00 \\
\hline NC3 & 3.50 & 1.56 & -0.85 & CP3 & 3.34 & 0.75 & -0.81 \\
\hline NC4 & 3.37 & 1.17 & -0.92 & CP4 & 3.88 & 0.59 & -0.61 \\
\hline NC5 & 3.50 & 1.91 & -0.87 & CP5 & 3.66 & 0.22 & -0.69 \\
\hline NC6 & 3.30 & - & - & CP6 & 3.45 & 0.14 & -0.57 \\
\hline
\end{tabular}

\section{Conclusions}

Investigation of carbon material addition to $\mathrm{TiO}_{2}$ in situ and the change in photoelectrochemical properties was carried out in this work. Comparison between commercial Pt doped carbon (CP) and synthesized $\mathrm{N}$ doped carbon (NC) shows that addition of these material can influence the structure of $\mathrm{TiO}_{2}$, as it was shown by XRD, but it seems that structural changes are not on the surface, as shown by Raman investigation. Theses structural changes can be attributed to decreased PCR values in CP series.

1. Commercial carbon doped with $\mathrm{Pt}$ decreases the photoelectrochemical properties of $\mathrm{TiO}_{2}$.

2. Self-synthesized NC carbon material doped with $\mathrm{N}$ increases the photoelectrochemical properties of $\mathrm{TiO}_{2}$.

3. $\mathrm{CP}$ introduction promotes $\mathrm{TiO}_{2}$ phase transition into rutile.

4. The change in photoelectrochemical properties can be attributed to the phase mixture for $\mathrm{CP}$ series.

Further investigation of surface $\mathrm{TiO}_{2}$ must be carried out to identify the source of the change of activity, weather it is a structural change or dopants. At this stage the dopant influence on pesticide degradation is not clear.

\section{Acknowledgements}

The authors greatly acknowledge financial support from the Latvian Science Council project LZP FLPP No. LZP-2018/1-0194.

\section{References}

[1] Kirchner C. et al., "Cytotoxicity of colloidal CdSe and CdSe/ZnS nanoparticles," Nano Lett., vol. 5, no. 2, Feb. 2005, pp. 331-338. 
[2] He Z., Tang J., Shen J., Chen J., Song S., "Enhancement of photocatalytic reduction of CO2 to CH4 over TiO2 nanosheets by modifying with sulfuric acid," Appl. Surf. Sci., vol. 364, Feb. 2016, pp. 416-427.

[3] Knoks A. et al., "Electro-catalytic and photo-catalytic reformation of CO 2 -reactions and efficiencies processes (Review)," IOP Conf. Ser. Mater. Sci. Eng., vol. 503, no. 1, Mar. 2019, p. 012009.

[4] Ma Y., Wang H., Yu J., Mo W., Yuan H. "Synergetic effect of carbon self-doping and TiO2 deposition on boosting the visible-light photocatalytic hydrogen production efficiency of carbon nitride,” Int. J. Hydrogen Energy, vol. 44, no. 12, Mar. 2019, pp. 5881-5889.

[5] Pichat P. Photocatalysis and Water Purification: From Fundamentals to Recent Applications. Weinheim, Germany: Wiley-VCH Verlag GmbH \&Co. KGaA, 2013.

[6] Vanags M. et al., "Sol-gel auto-combustion synthesis of $\mathrm{Ca} 2 \mathrm{Fe} 2 \mathrm{O} 5$ brownmillerite nanopowders and thin films for advanced oxidation photoelectrochemical water treatment in visible light," J. Environ. Chem. Eng., vol. 7, no. 4, Aug. 2019, p. 103224.

[7] Wang H., Li Y., Ba X., Huang L., Yu Y. "TiO2 thin films with rutile phase prepared by DC magnetron co-sputtering at room temperature: Effect of Cu incorporation," Appl. Surf. Sci., vol. 345, Aug. 2015, pp. 49-56.

[8] Yu J. et al., "A cylindrical core-shell-like $\mathrm{TiO} 2$ nanotube array anode for flexible fiber-type dyesensitized solar cells.," Nanoscale Res. Lett., vol. 6, no. 1, Jan. 2011, 94 p.

[9] Macak J. M. et al., "TiO2 nanotubes: Self-organized electrochemical formation, properties and applications," Curr. Opin. Solid State Mater. Sci., vol. 11, no. 1-2, Feb. 2007, pp. 3-18.

[10] Knoks A., Kleperis J., Grinberga L. "Raman spectral identification of phase distribution in anodic titanium dioxide coating," Proc. Est. Acad. Sci., vol. 66, no. 4,2017, 422 p.

[11] Wang Y. et al., "TiO2 nanoparticles in the marine environment: Physical effects responsible for the toxicity on algae Phaeodactylum tricornutum," Sci. Total Environ., vol. 565,2016, pp. 818-826.

[12]Žerjav G., Arshad M. S., Djinović P., Zavašnik J., Pintar A. "Electron trapping energy states of TiO2-WO3 composites and their influence on photocatalytic degradation of bisphenol A," Appl. Catal. B Environ., vol. 209,2017, pp. 273-284.

[13] Varnagiris S., Medvids A., Lelis M., Milcius D., Antuzevics A. "Black carbon-doped TiO2 films: Synthesis, characterization and photocatalysis," J. Photochem. Photobiol. A Chem., vol. 382, Sep. 2019, p. 111941.

[14] Rajaraman T. S., Parikh S. P., Gandhi V. G., "Black TiO2: A review of its properties and conflicting trends," Chemical Engineering Journal, vol. 389. Elsevier B.V., p. 123918, Jun. 01, 2020.

[15] Pérez-Jiménez L. E. et al., "Enhancement of optoelectronic properties of TiO2 films containing Pt nanoparticles," Results Phys., vol. 12, Mar. 2019, pp. 1680-1685.

[16] Nikokavoura A., Trapalis C. "Alternative photocatalysts to $\mathrm{TiO} 2$ for the photocatalytic reduction of CO2,” Appl. Surf. Sci., vol. 391,2017, pp. 149-174.

[17] Sayes C. M. et al., "Correlating nanoscale titania structure with toxicity: A cytotoxicity and inflammatory response study with human dermal fibroblasts and human lung epithelial cells," Toxicol. Sci., vol. 92, no. 1, Jul. 2006, pp. 174-185.

[18] Olins R., Lesnicenoks P., Kleperis J., Knoks A., Lukosevics I. "Electrochemical exfoliationstreamline method for synthesis of nitrogen doped graphene," Chemija, vol. 32, no. 1, Feb. 2021, pp. 9-16.

[19] Mott N. F. "The theory of crystal rectifiers," Proc. R. Soc. London A Math. Phys. Eng. Sci., vol. 171 , no. 944,1939 , pp. 27-38.

[20] Gelderman K., Lee L., Donne S. W. "Flat-Band Potential of a Semiconductor: Using the MottSchottky Equation,” J. Chem. Educ., vol. 84, no. 4,2007, 685 p.

[21] Radecka M., Rekas M., Trenczek-Zajac A., Zakrzewska K., "Importance of the band gap energy and flat band potential for application of modified TiO2 photoanodes in water photolysis," J. Power Sources, vol. 181, no. 1, Jun. 2008, pp. 46-55.

[22] Ohsaka T., Izumi F., Fujiki Y., "Raman spectrum of anatase, TiO2," J. Raman Spectrosc., vol. 7, no. 6, Dec. 1978, pp. 321-324.

[23] Balachandran U., Eror N. G. "Raman spectra of titanium dioxide," J. Solid State Chem., vol. 42, no. 3, May 1982, pp. 276-282. 
[24] Porto S. P. S., Fleury P. A., Damen T. C. "Raman Spectra of TiO2, MgF2, ZnF2, FeF2, MnF2," Phys. Rev., vol. 154, no. 2, Feb. 1967, pp. 522-526.

[25] Kubelka P. "New Contributions to the Optics of Intensely Light-Scattering Materials Part I," J. Opt. Soc. Am., vol. 38, no. 5, May 1948, 448 p.

[26] Tauc J. "Optical properties and electronic structure of amorphous Ge and Si," Mater. Res. Bull., vol. 3, no. 1, Jan. 1968, pp. 37-46.

[27] Beranek R. "(Photo)electrochemical methods for the determination of the band edge positions of TiO2-based nanomaterials,” Adv. Phys. Chem., vol. 2011,2011, pp. 80-83. 